\title{
The incidence of nursing students' perceived stress and burnout levels at a private university in California
}

\author{
Reo J.F. Jones ${ }^{1}$, Margaret M. Hansen ${ }^{* 2}$, Mahmoud Kaddoura ${ }^{2}$, Aimee Schwab-McCoy ${ }^{3}$, Kirsten Tocchini ${ }^{2}$ \\ ${ }^{1}$ Nebraska Medicine, Omaha, Nebraska, United States \\ ${ }^{2}$ School of Nursing and Health Professions, University of San Francisco, California, United States \\ ${ }^{3}$ Department of Mathematics, Creighton University, Omaha, Nebraska, United States
}

Received: April 4, 2018

DOI: $10.5430 /$ jnep.v8n10p138
Accepted: May 15, 2018

Online Published: May 29, 2018

URL: https://doi.org/10.5430/jnep.v8n10p138

\begin{abstract}
Background and objective: Historically, there has been a paucity of research regarding stress and burnout in nursing students. However, during the past five years research focusing on the predictors associated with stress and burnout has been conducted. Continued research contributions to the nursing education literature are necessary due to the current $70 \%$ nursing burnout rate. The aim of this study was to explore undergraduate and graduate nursing students' perceived stress and burnout in order to design a future intervention study.

Methods: Pollock's Nursing Adaptation Model served as a conceptual framework. Correlational descriptive non-interventional survey design was used to gather data from consented participants $(\mathrm{N}=217)$. The Perceived Stress Scale and Maslach's Burnout Inventory were provided. Data were analyzed using descriptive statistics, one-way analysis of variance, and multiple comparison $t$-tests (Tukey's adjustment).

Results: Students who spent more time per week on homework and studying for exams tended to be more stressed and cynical. Students enrolled in graduate level courses tended to be more cynical and exhausted. Undergraduate students demonstrated a stronger sense of professional efficacy. Students who spent less than five hours studying for exams per week reported more exhaustion, suggesting external factors may be influential. Certain recreational activities were found to be related to stress, cynicism and exhaustion levels, suggesting students with a recreational outlet may be better able to cope. Significant associations between students' hours spent on academic work and family circumstances may provide an explanation of academic pressures. Conclusions: Our findings highlight nursing students having significantly higher stress and cynicism levels associated with the amount of homework and study hours for exams per week. Furthermore, students studying less reported being more exhausted. Collaboratively, nurse educators and students are wise to develop healthy interventions to enhance students' health and learning. Reportedly, healthcare providers are experiencing burnout and unhealthy stress-coping behaviors. Educators are in a position to role model and educate healthy lifestyle choices.
\end{abstract}

Key Words: Stress, Burnout, Nursing, Students, Education

\section{INTRODUCTION}

Prolonged exposure to excessive stress, which results in the overproduction of adrenaline and cortisol, combined with a lack of self-awareness and self-care, can ultimately lead to physiological disease, occupational burnout and emotional exhaustion. The amount and quality of stress experienced by

\footnotetext{
* Correspondence: Margaret M. Hansen; Email: mhansen@usfca.edu; Address: School of Nursing and Health Professions, University of San Francisco, San Francisco, California, United States.
} 
individuals varies depending upon many factors. One factor is a person's occupation. The high incidence of stress among healthcare providers has been documented and remains a genuine concern of the healthcare industry. ${ }^{[1]}$

The National Institute of Occupational Safety and Health (NIOSH) defines occupational stress as, "the harmful physical and emotional responses that occur when the requirements of the job do not match the capabilities, resources, or needs of the worker". ${ }^{[1]}$ The deleterious responses to chronic stress may lead to increased absenteeism, individual intent to leave a profession, burnout, reduced patient satisfaction, and diagnosis and treatment errors. Moreover, the psychological distress outcomes related to undue stress as reported in the literature include: substance abuse, suicide, anxiety and depression. ${ }^{[1]}$

Congruently, "burnout" surfaces from chronic stress and has been identified as a syndrome. The syndrome is characterized by feelings of emotional exhaustion, depersonalization and reduced personal accomplishments. ${ }^{[2]}$ As a result of this depersonalization, negative, cynical attitudes and feelings, could be projected towards others. Research indicates that nursing students are at risk for both chronic stress and feelings of burnout while attempting to meet the demands of rigorous studies. ${ }^{[3]}$

In a pioneering literature review, which elucidates the correlation between nursing students and stress, Labrague presents 13 articles from around the world that all lead to a similar conclusion. $^{[3]}$ In an aim to review the stress and coping methods of nursing students, studies show that too much stress is detrimental to both the physiological and psychological health of nursing students, the effective acquisition of knowledge and the practice of nursing. ${ }^{[3]}$ Furthermore, nurse educators and hospital staff have the responsibility of fostering an environment for learning that both reduces stress and promotes effective coping strategies. In another review of literature that included 13 studies, Alzayyat and Al-Gamal found common themes of stress were evident throughout a nursing student's initial clinical experience, comparison among academic years, exposure to cross-cultural differences, as well as various clinical experiences. ${ }^{[4]}$ Common themes of fear, incivility, inconsistency, and time constraints contributed to the stress of nursing students in a review of literature presented by Wallace. ${ }^{[5]}$ The study's purpose was to determine which situations were perceived by students as causing the most stress. Situations for which students were surveyed related to doing something new and unfamiliar or making a mistake, behaviors of healthcare staff toward students, as well as the behaviors of instructors and other nurse educators. ${ }^{[5]}$ The results confirmed previous findings that too much stress in these situations not only discourages the nursing student, but by attrition perpetuates a lack of communication and a hierarchical disciplinary approach to nursing education. ${ }^{[5]}$

In a quantitative review of 13 studies, Benevente and Costa found stress had both psychological and physiological effects for nursing students. ${ }^{[6]}$ Physiologically, lumbar pain, changes in immunoglobulin levels, an increase in cortisol levels, as well as, decreased immune function are products of stress for nursing students. ${ }^{[6]}$ Psychologically, nursing students are at risk for depression and other mental disorders due to stress. ${ }^{[6]}$ In a cross-sectional study by Kang, 77 graduating baccalaureate nursing students completed questionnaires and provided a saliva sample during the fall semester of 2013. ${ }^{[7]}$ Based on salivary cortisol indicators and survey responses, over $30 \%$ of the students reported relatively high levels of stress that further indicated a potentially increased risk for compromising their health and well-being. ${ }^{[7]}$

A nursing student's stress is often relieved by methods of both effective and ineffective coping. Shinde \& Hiremath conducted a study with a sample of 323 baccalaureate nursing students, $65.6 \%$ reported having moderate stress, $18.6 \%$ students rated their stress as mild, and $15.8 \%$ claimed to have severe stress. ${ }^{[8]}$ As for methods of coping with this stress, $50 \%$ of students used positive thinking, $37 \%$ used emotional support, $65 \%$ had social support, $25 \%$ used spiritual support, and $30 \%$ students reduced their stress by diversional activity. ${ }^{[8]}$ Only $13.6 \%$ rated themselves as having good coping ability, with $70.9 \%$ of students having reported moderate coping methods, and $15.5 \%$ having poor coping methods. Hirsch (2014) developed a cross-sectional study conducted with 146 nursing students. ${ }^{[9]}$ The results show that in comparisons between various stressors to coping strategies, professional education, denial of problem, acquired practical knowledge and escape-avoidance presented the highest correlation values, between 0.21 and $0.40 .{ }^{[10]}$ Hirsch found that the most common strategies used by students in stressful events were considered negative and of poor effectiveness, as efforts were focused on emotions and not on the problem, compromising students' professional training process. ${ }^{[9]}$

In a quantitative systematic review of 16 studies, Galbraith and Brown found relaxation and cognitive reappraisal techniques were most effective in relieving nursing students' stress. ${ }^{[10]}$ Furthermore, a longitudinal study conducted with a population of 46 nursing students, Hensel and Laux found that while perception of professional identity and the importance of self-care increased over time in the workforce as a nurse, stress levels decreased. ${ }^{[1]}$ These findings demonstrate that it would be paramount for nurses to exercise self-care 
and utilize successful coping methods for stress reduction so that patient-care isn't compromised.

The aim of this cross-sectional survey study was to assess private university undergraduate and graduate nursing students' perceived stress levels and burnout during the 2017 fall academic semester by using the Perceived Stress Scale ${ }^{[12]}$ and Maslach's Burnout Inventory. ${ }^{[13]}$ The mission statement of the university states that its' graduates will be prepared "health professionals that address the determinants of health, promote policy and advocacy and provide a moral compass to transform health care in order to further equity, and positively influence quality, delivery, and access". [14] With the specific aim of their academic achievement upon graduation in mind, this study expands the current literature in successfully identifying specific factors that affect a nursing student's perceived stress and burnout during one semester of their education. Additionally, this study helps to identify which coping methods should be further studied so that as licensed healthcare providers, nurses, and nursing students alike will have evidenced based practice to follow for their own self-care.

\section{Methods}

\subsection{Conceptual Model}

From the physiological and psychological stress pioneers, Seyle and Lazarrus, as well as the adaptation experts, Roy and Helson, emerged Pollock's original Nursing Adaptation Model in 1984. ${ }^{[15]}$ Through personal reflection and revisions,
Pollock's model (see Figure 1) supports the profession of nursing, nursing students' experiences, and focuses on the human characteristic of 'hardiness' as a panacea for a human stress-illness relationship. Human 'hardiness' is seen as a way of directly coping with the stress-illness response and indirectly influencing the human's perception of stress that may or may not influence a stress-illness response. Roy's adaptation model ${ }^{[16]}$ is well known in the nursing literature and is easily identified in Pollock's model. Similar to Roy's adaptation model, Pollock states 'adaptation' is an active process between an individual and the environmental surroundings and, is considered effective if it enhances both the psychological and physiological well-being of the individual.

In 1956, Hans Seyle, hypothesized human stress stemmed from psychology's known 'stimulus-response' and went on to describe the stress-response as being a general adaptation syndrome that includes (1) the alarm reaction, (2) the stage of resistance and, (3) the stage of exhaustion. ${ }^{[15]}$ In regards to coping strategies by the unique individual, Lazares explained the individual assessment of the stressor determines the psychological component of the stress response. These influential pioneers of the stress response highly influenced Pollock's definition of stress: "the whole set of physiologic and psychologic phenomena including the objective event or stressor, the person's perception of the stressor, the conditioning factors or contextual stimuli, the various intervening processes or the residual stimuli, and the manifestations of response to the stressor". [16]

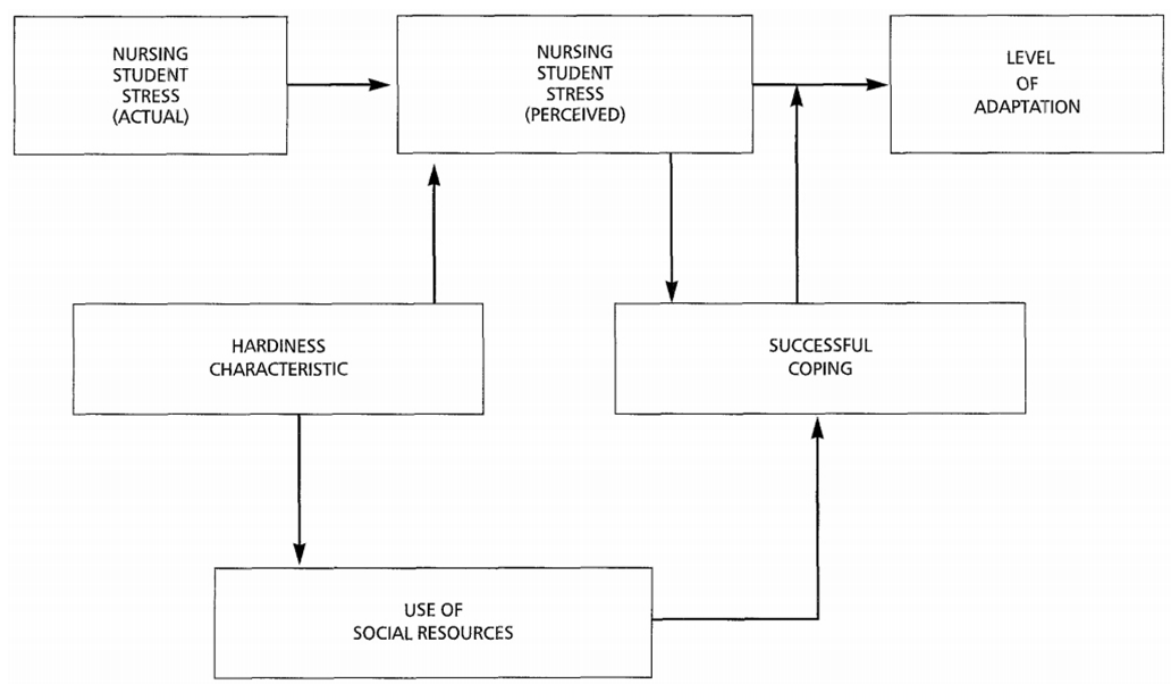

Figure 1. The adaptation model (revised)

\subsection{Research design}

The correlational descriptive non-interventional survey design was used to gather data since it is the most appropriate technique in assessing the perceived stress and burnout ex- perienced by the students. No intervention was used as the focus of the study was assessment of the nursing students' perceived level of stress and burnout. 
The dependent variables for this study consisted of the three subsets of burnout: exhaustion, cynicism, and professional efficacy as measured by the Maslach Burnout Inventory General Survey (Students) [MBI-GS (S)]. ${ }^{[17]}$ The other dependent variable was the stress level as measured by the Perceived Stress Scale (PSS).

The independent variables included the students' age, gender, semester in school, marital status, program level (BSN vs. MSN), whether living with a significant other or spouse, homework hours per week, study hours per week, meditation, walking, and camping.

\subsection{Research setting}

This study was conducted at a School of Nursing (SON) in a private university in California that enrolls a large number of undergraduate and graduate nursing students. The participants of this study were Bachelor of Science in nursing (BSN) and Masters of Science in nursing (MSN) students from three different campuses across the state of California; campus $\mathrm{A}$, campus $\mathrm{B}$, and campus $\mathrm{C}$.

\subsection{Sample}

Approximately 300 students (sophomore BSN, junior BSN, senior BSN, and MSN students) who were studying at the SONHP at the time of the study, were approached during the fall 2017 academic semester. At that time, the research assistants (RAs) obtained consent from 254 students and 217 students returned completed online surveys. The total response rate was $85 \%$. A total convenience sample of 217 students from three campuses of the university participated in the study.

\subsection{Ethics}

The university's Institutional Review Board for the protection of human subjects (IRBPHS) approved this study prior to data collection. An informed consent was obtained from those students who agreed to complete the surveys. Participation was voluntary. No personally identifiable information was requested, and responses remained anonymous and confidential. Each participant was informed of benefits and risks connected with participating in this study and the rights to withdraw from the study at any time without affecting their status, as student or employee, at the SON. Students were also informed that their data may be used for publications, and will be presented in the aggregate. Data were kept confidential and stored in the PI's office for six months.

\subsection{Instruments}

All participants completed a demographic survey, two valid and reliable instruments; the Perceived Stress Scale (PSS)

Published by Sciedu Press and the Maslach Burnout Inventory General Survey (Students) [MBI-GS (S). The approximate time to complete all surveys ranged between ten (10) and twenty (20) minutes.

The Perceived Stress Scale (PSS) is the most widely used psychological instrument for measuring the perception of stress. It is a 16-question self-administered questionnaire, which has been reliable and valid, easy to administer, and takes 10-15 minutes to fill out. It is a measure of the degree to which situations in one's life are appraised as stressful. Items are designed to tap how unpredictable, uncontrollable, and overloaded respondents find their lives. The questions in the PSS ask about feelings and thoughts during the last month. In each case, respondents are asked how often they felt a certain way. The scale also includes a number of direct queries about current levels of experienced stress. ${ }^{[18]}$

The PSS was designed for use in community samples with at least a junior high school education. The items are easy to understand, and the response alternatives are simple to grasp. Moreover, the questions are of a general nature and hence are relatively free of content specific to any subpopulation group. The scale yielded a single score, with high scores indicating higher levels of stress and lower levels indicating lower levels of stress. The PSS scores are obtained by reversing responses (e.g., $0=4,1=3,2=2,3=1 \& 4=0$ ) to the four positively stated items (items $4,5,7, \& 8$ ) and then summing across all scale items. A short 4-item scale can be made from questions 2, 4, 5 and 10 of the PSS 10 item scale. ${ }^{[12]}$

The current findings reveal the PSS is a reliable and valid instrument for assessment of perceived stress in college students. It has demonstrated adequate reliability coefficients; Cronbach's alpha ranging from 0.78 to 0.91 and test-retest reliability coefficients of $0.55-0.80 .{ }^{[12]}$ The PSS has also shown validity evidence compared to health behaviors, perceived health, and stressful life events and negative affect as criterion measures. $^{[12]}$

The Maslach Burnout Inventory General Survey (Students) [MBI-GS (S)] was designed for use with adult students in college and university to measured burnout from the perspective of one's performance at work in general. It is a self-administered questionnaire, which has been reliable and valid, easy to administer, and takes 10-15 minutes to fill out. $^{[13]}$

It comprises 16 items clustered in three subscales, namely professional efficacy, exhaustion and cynicism. Professional efficacy encompassed. The emotional exhaustion scale describes feelings of being overextended and exhausted by one's studies and physical and emotional resource depletion. The cynicism scale measures an indifference towards work 
and the development of negative attitudes toward work in general. due to coping with exhausting demands. It describes an impersonal and distant attitude towards one's studies and job and not only towards recipients of one's work. The professional efficacy scale measures satisfaction with past and present accomplishments and it explicitly assesses an individual's expectations of continued effectiveness at school. It describes feelings of achievement in one's work. High scores on the first two subscales and low scores on the third subscale indicate the presence of burnout. ${ }^{[13]}$

Iwanicki and Schwab (1981) validated the three-factor structure of the MBI instrument. Their measure of internal consistency yielded a Cronbach's alpha coefficient of $0.90 .^{[19]}$

In terms of the validity of the MBI, there seems to be sufficient evidence for the convergent validity of the scale. The validity, established by gathering data in different ways to demonstrate convergence on the same construct, was established by the expected relationships of correlations of MBI scores with independent behavioral ratings of significant others, job characteristics expected to contribute to burnout and measures of various outcomes hypothesized to be related to burnout. ${ }^{[13]}$ In order to differentiate the MBI from other constructs and explain why they are/are not related to the construct of burnout, relationships between burnout and concepts such as job satisfaction, depression and social desirability were investigated. Small but significant positive relationships were found between different measures of satisfaction and the MBI-HSS Scales. ${ }^{[13]}$

\subsection{Data collection and analyses}

The primary investigators (PIs) contacted the school administrator for the current list of BSN and MSN nursing students enrolled at the SON in the Fall Semester 2017. The administrator also provided the names of the professors teaching in this semester and their school email addresses, the classes they teach and the number of students in each class across the three school campuses.

The PIs sent out an initial email to all professors teaching the prospective student participants during the first week of classes. They introduced the study and requested the faculty's permission to utilize their classroom time for no more than 15 minutes to facilitate the data collection process. Feedback was asked to be received from professors within two weeks. The PIs sent two follow-up emails to the professors who expressed interest and introduced the two RAs, who are not involved in teaching or supervising any of the students.

The RAs coordinated with the professors an appropriate time to schedule class visits and/or send a video describing the data collection method, including the consent form. The RAs then visited the classes on campus $A$ and presented the research study to the students following a set script. and explained to the students the nature and purpose of study and the students' rights. Also, the informed consent was provided and the students were asked to complete the online surveys. Each participating class on campus A was read the instructions for the surveys and any questions regarding clarification of the instructions were answered by the RAs. Hard copies of the consent form and the survey link were also distributed to the students. All students were provided links to the survey. The RAs sent the students an electronic invitation via email informing them of the survey, its purpose and the dates that the surveys were available, should they wish to participate.

For off site campuses, B and C, a video was made by the RAs and was sent to the professors of those campuses along with a PDF version of the consent form. The professors then sent the information to their respective students or showed them the video in class. The video contained the same script and instructions used for campus A students. All students were given access to a PDF link to the informed consent. The RAs then sent two reminder emails to all the professors to remind their students to complete the surveys before the determined deadline.

Data were collected using a demographic survey and two selfadministered surveys on stress (the PSS survey) and burnout (the MBI-GS (S) survey), which were prepared by Mind Garden (C), a Palo Alto, CA based company, and delivered to the students via a URL. The data were analyzed using descriptive statistics and multivariate analysis, using $\mathrm{R}$ version 3.4.3 ${ }^{[20]}$ and RStudio. One-way analysis of variance (ANOVA) was used to look for significant differences in stress levels, exhaustion, cynicism, and professional efficacy. Effect sizes for significant differences between pairwise groups were estimated using Tukey's honest significant differences.

\section{RESULTS}

As shown in Table 1, a student's age, primary language spoken at home, year in their academic program, whether or not they lived with a spouse, and academic commitments had significant effects on stress levels, cynicism, exhaustion, and professional efficacy. There was no significant effect of gender, certain family characteristics (having children, pets, or being a caregiver), living situation (living with parents, roommates, and general living environment), external environment (having access to a greenspace/garden or living near a park or nature trail), or employment status on student pressures. 
Table 1. One-way ANOVA tests of significant differences

\begin{tabular}{llll}
\hline Explanatory & Response & F-statistic & $p$-value \\
\hline \multirow{2}{*}{ Age } & Cynicism & $\mathrm{F}_{4,209}=6.05$ & .0001 \\
Primary language spoken at home & Exhaustion & $\mathrm{F}_{4,209}=3.03$ & .0185 \\
& Exhaustion & $\mathrm{F}_{1,215}=4.32$ & .0389 \\
Year & Cynicism & $\mathrm{F}_{3,213}=8.64$ & $<.0001$ \\
& Exhaustion & $\mathrm{F}_{3,213}=6.327$ & .0004 \\
Living with a significant other or spouse & Professional Efficacy & $\mathrm{F}_{3,213}=3.60$ & .0143 \\
& Cynicism & $\mathrm{F}_{1,215}=9.68$ & .0021 \\
Hours spent doing homework each week & Exhaustion & $\mathrm{F}_{1,215}=3.73$ & .0547 \\
& Stress & $\mathrm{F}_{4,212}=2.66$ & .0336 \\
Hours spent studying for exams each week & Cynicism & $\mathrm{F}_{4,212}=2.64$ & .0351 \\
& Exhaustion & $\mathrm{F}_{4,212}=3.52$ & .0083 \\
& Stress & $\mathrm{F}_{4,212}=3.57$ & .0076 \\
\hline
\end{tabular}

Stress levels were found to be significantly related to academic commitments (hours spent doing homework and studying for exams). Specifically, students who spent more than 20 hours per week on homework were significantly more stressed than students spending only 1-5 hours on homework per week $(\mathrm{d}=5.5, p=.015)$. For exams, students who spent more than 20 hours per week studying were significantly more stressed than students studying 6-10 hours per week $(\mathrm{d}=4.02, p=.018)$ and students studying 16-20 hours per week were somewhat more stressed than students studying 6 -10 hours per week $(d=4.13, p=.080)$. This suggests that students who spend more time per week studying for exams or doing homework tend to be more stressed overall. These students may be stressed as a result of their increased time on academic work, or may be spending more time on academics as a result of their stress.

Cynicism scores on Maslach's Burnout Inventory (MBI) were significantly related to a student's age, year and program, whether or not a student lives with a spouse or significant other, and time spent doing homework each week. 18-23-year olds tended to be least cynical, and were significantly less cynical than 24-28-year olds $(d=-0.85, p=.002)$ and 29-33-year olds $(\mathrm{d}=-1.34, p=.003)$. Students in the graduate program were found to be significantly more cynical than sophomores $(\mathrm{d}=1.04, p=.000)$, and students living with a romantic partner were significantly more cynical than those not living with a romantic partner $(\mathrm{d}=-0.48, p=.055)$. This could be due to associations between age, program, and whether or not students lived with a romantic partner, as all three are significantly related. Students spending more than 20 hours on homework were found to be significantly more

Published by Sciedu Press cynical than students spending 6-10 hours $(\mathrm{d}=0.98, p=$ .045) and somewhat more cynical than students spending $16-20$ hours $(\mathrm{d}=1.15, p=.071)$. On average, the more time spent on homework per week, the more cynical a student tended to be.

Exhaustion scores were significantly affected by a student's age, primary language spoken at home, year and program, and academic commitments. Students between the ages of 24 and 28 were most exhausted overall, and significantly more exhausted than $18-23$ year olds $(\mathrm{d}=0.67, p=.04)$ and somewhat more exhausted than 34-38-year olds $(\mathrm{d}=1.43, p$ $=.095)$. Students whose primary language was English were significantly more exhausted than students whose primary language was not English $(\mathrm{d}=1.08, p=.039)$. Students in the MSN program were significantly more exhausted than undergraduate students $(\mathrm{d}=0.84, p=.000)$. Students with more than 20 hours of homework per week were significantly more exhausted than students with 1-5 hours of homework $(\mathrm{d}=$ $1.27, p=.011)$, students with 11-15 hours of homework $(\mathrm{d}=$ $1.12, p=.022$ ), and students with 16-20 hours of homework $(\mathrm{d}=1.43, p=.013)$. These students were somewhat more exhausted than students with 6-10 hours of homework ( $d=$ $0.902, p=.086$ ). Students studying more than 20 hours per week are significantly more exhausted than students studying 6-10 hours $(d=0.814, p=.049)$.

Professional efficacy scores were related to hours spent studying for exams and year in program. Surprisingly, graduate students had significantly lower professional efficacy than BSN students $(\mathrm{d}=-0.35, p=.024)$. Students who study more than 20 hours had significantly higher professional efficacy than students who study $1-5$ hours $(\mathrm{d}=0.71, p=.021)$, as 
did students who studied 6-10 hours $(\mathrm{d}=0.54, p=.044)$.

Certain recreational activities were found to help students cope with the stresses of their academic programs and work. For example, meditation was found to be significantly related to higher professional efficacy $(\mathrm{d}=0.542, p=.0009)$, and somewhat associated with lower cynicism levels $(\mathrm{d}=$ $-0.405, p=.078)$ and lower exhaustion levels $(\mathrm{d}=-0.413, p=$ .078). Students who walked regularly reported significantly higher professional efficacy levels than students who did not ( $\mathrm{d}=0.355, p=.024)$, and students who enjoyed camping reported lower stress levels $(\mathrm{d}=-2.437, p=.039)$. These results should not be taken as absolutely suggestive that particular recreational activities will lead to positive impacts in a certain aspect of a student's life, since there are likely confounding variables and the sample sizes for some activ- ities are small (see Table 2). However, this provides some evidence that regular recreational activity may have positive effects on a student's ability to successfully deal with the pressures of their programs.

Some family characteristics (having children, pets, or being a caregiver), living situation (living with parents, roommates, and general living environment), external environment (having access to a greenspace/garden or living near a park or nature trail), employment status were all found to have no significant effect on student stress, cynicism, exhaustion, or professional efficacy.

Students who had more than 20 hours of homework per week tended to rate themselves as more stressed on average compared to other levels time spent doing homework (see Figure 2).

Table 2. Summary statistics, reported as mean (standard deviation), and group sizes for recreational activities with significant differences in stress, cynicism, exhaustion, and/or professional efficacy

\begin{tabular}{llll}
\hline Recreational activity & Response & Yes & No \\
\hline \multirow{3}{*}{ Meditation } & Cynicism & $1.92(1.32)$ & $2.33(1.44)$ \\
& Exhaustion & $3.30(1.66)$ & $3.71(1.37)$ \\
& Professional Efficacy & $4.76(0.86)$ & $\mathrm{n}=1.22(1.04)$ \\
Walking & Sample size & $\mathrm{n}=50$ & $4.08(1.16)$ \\
& Professional Efficacy & $4.44(0.96)$ & $\mathrm{n}=58$ \\
Camping & Sample size & $\mathrm{n}=159$ & $21.07(6.35)$ \\
& Stress & $8.63(6.45)$ & $\mathrm{n}=182$ \\
\hline
\end{tabular}

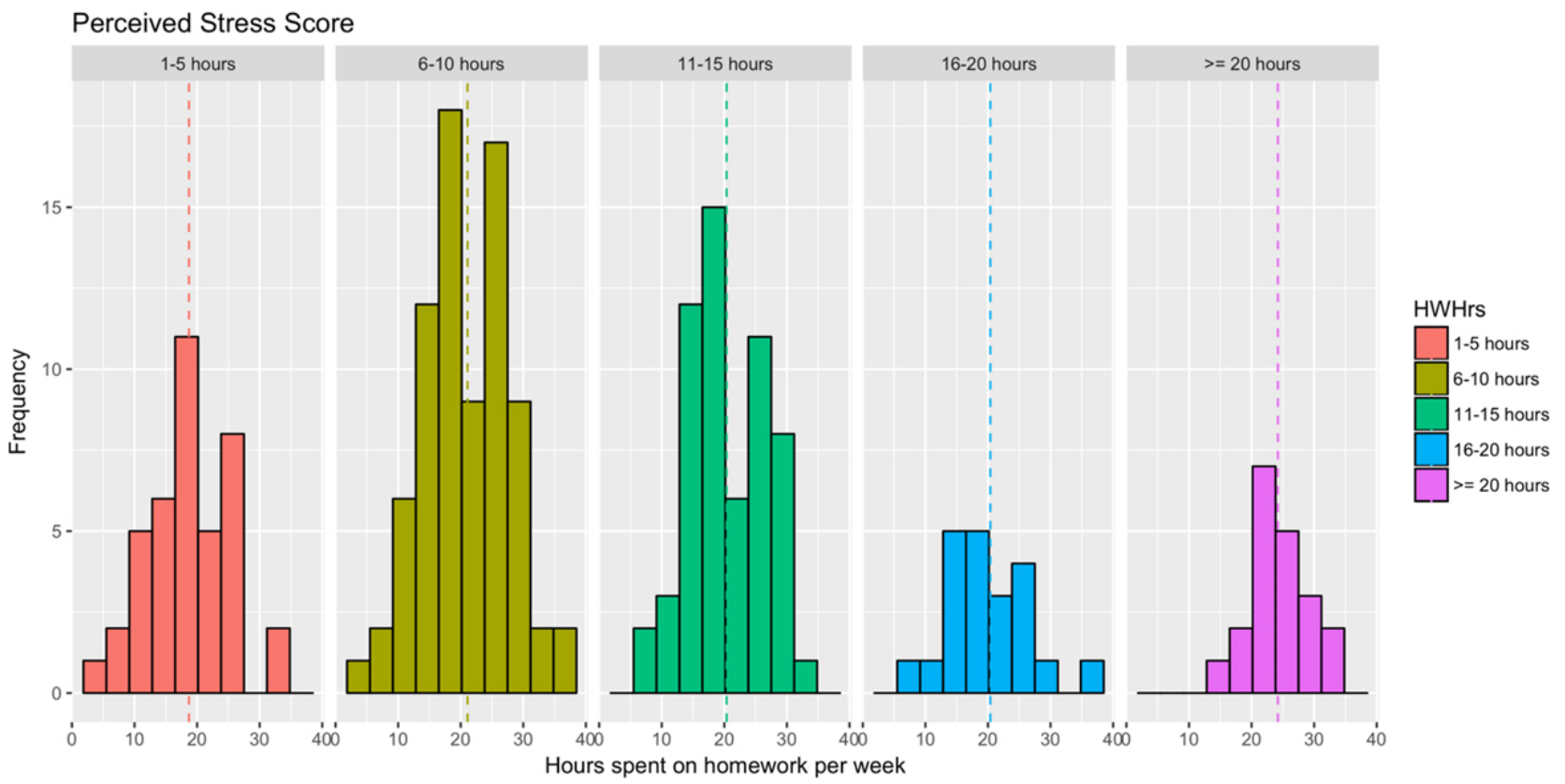

Figure 2. Perceived stress level grouped by hours spent doing homework 
Table 1 shows the results of a one-way ANOVA test for sta- Students who spent more than 16 hours per week studying tistically significant differences in stress levels, cynicism, for exams tended to be more stressed on average compared exhaustion, or professional efficacy for each of the explana- to students who spent less time studying (see Figure 3). tory variables considered.

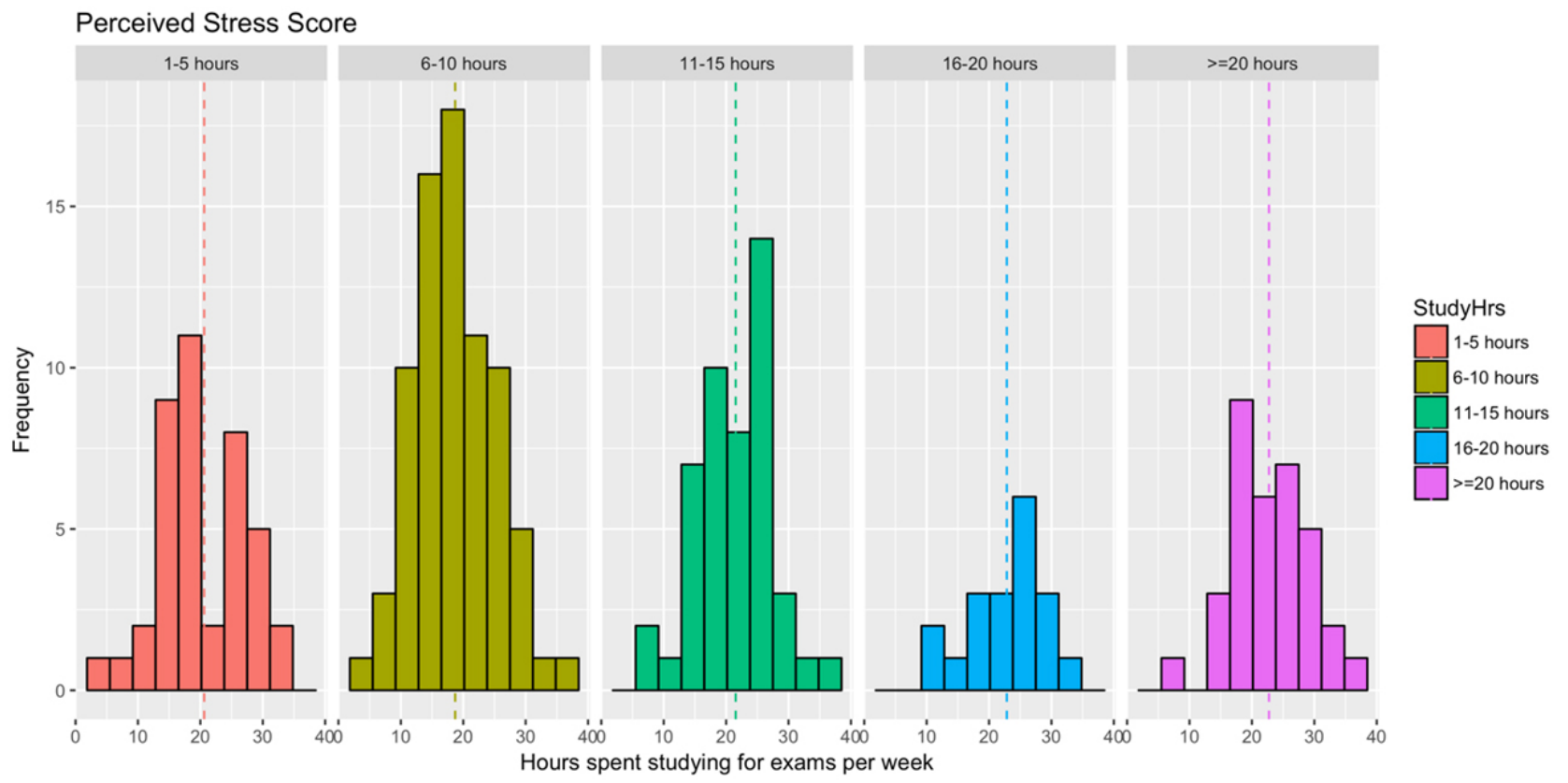

Figure 3. Perceived stress level grouped by hours spent studying for exams

Students between the ages of 24-33 tended to be more cyni- MSN students were significantly more cynical on average cal, on average. Students younger than age 24 and older than than undergraduate students (see Figure 5). age 33 were less cynical on average (see Figure 4).

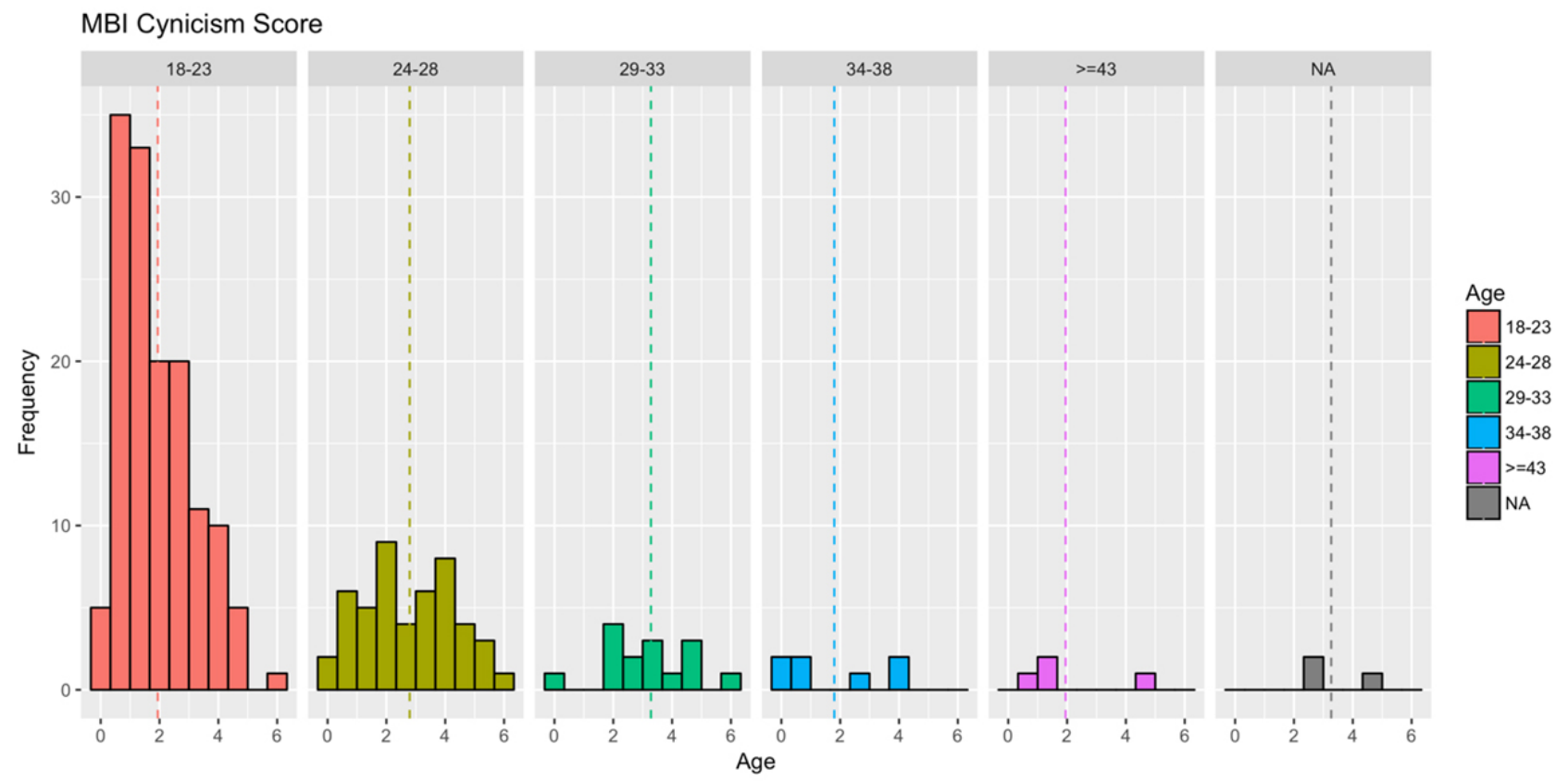

Figure 4. MBI Cynicism score grouped by age 
Students living with a significant other or spouse tended to be more cynical on average than students who didn't. This may be a result of significant associations between living with a romantic partner, age, and program (see Figure 6).

Students with more than 20 hours of homework per week were significantly more cynical than those with less than 20 hours of homework per week (see Figure 7).

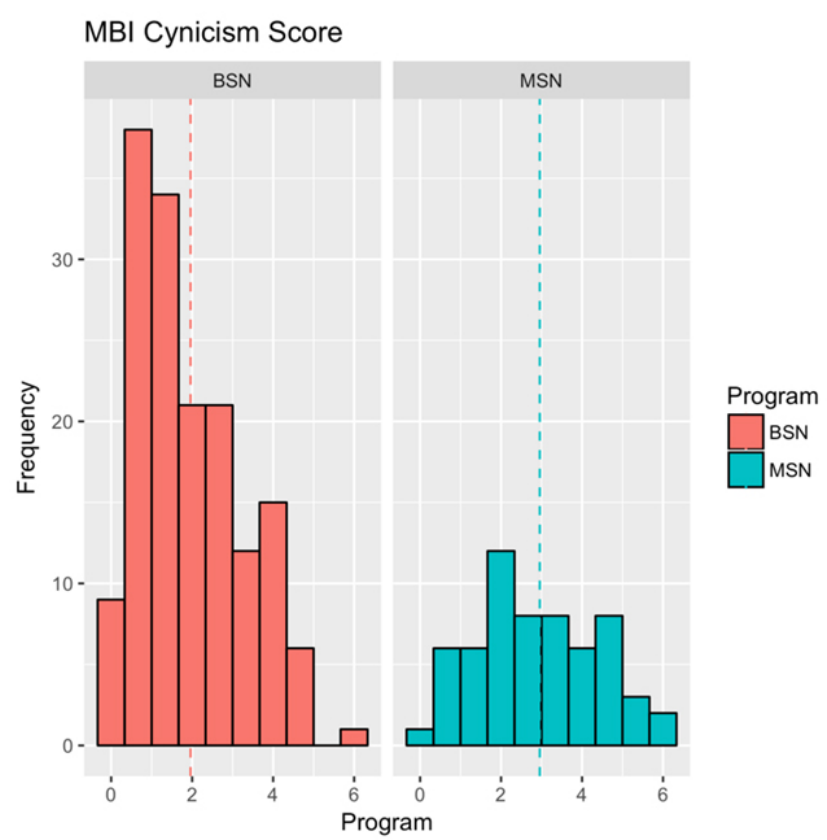

Figure 5. MBI Cynicism score grouped by program

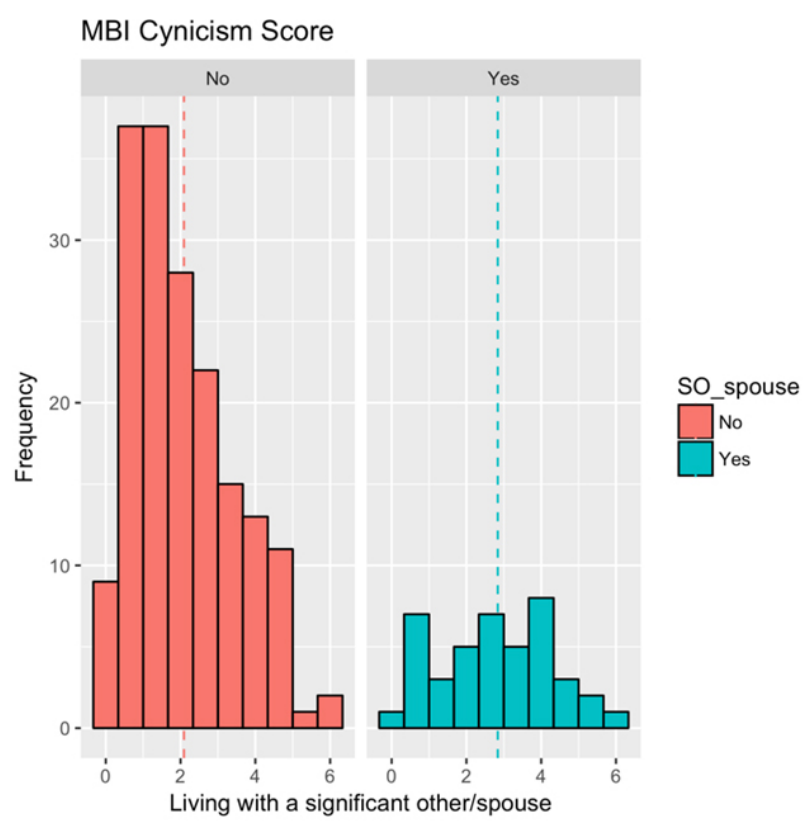

Figure 6. MBI Cynicism score grouped by whether students live with a significant other or spouse

Students between the ages of 24 and 33 were the most exhausted, on average (see Figure 8).

Students with more than 20 hours of homework per week or between 6-10 hours of homework per week tended to report higher exhaustion (see Figure 9).

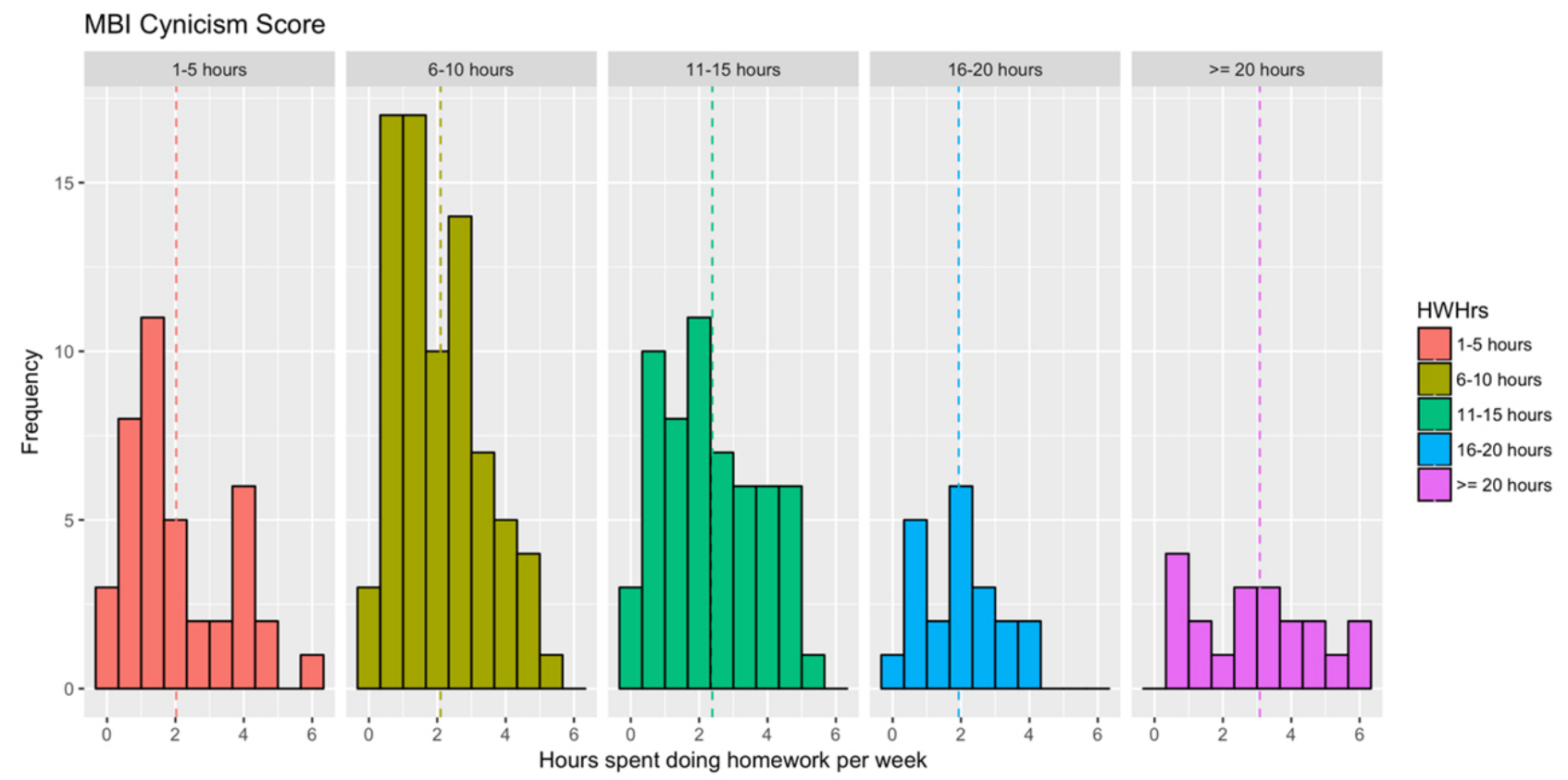

Figure 7. MBI Cynicism score grouped by hours spent doing homework 


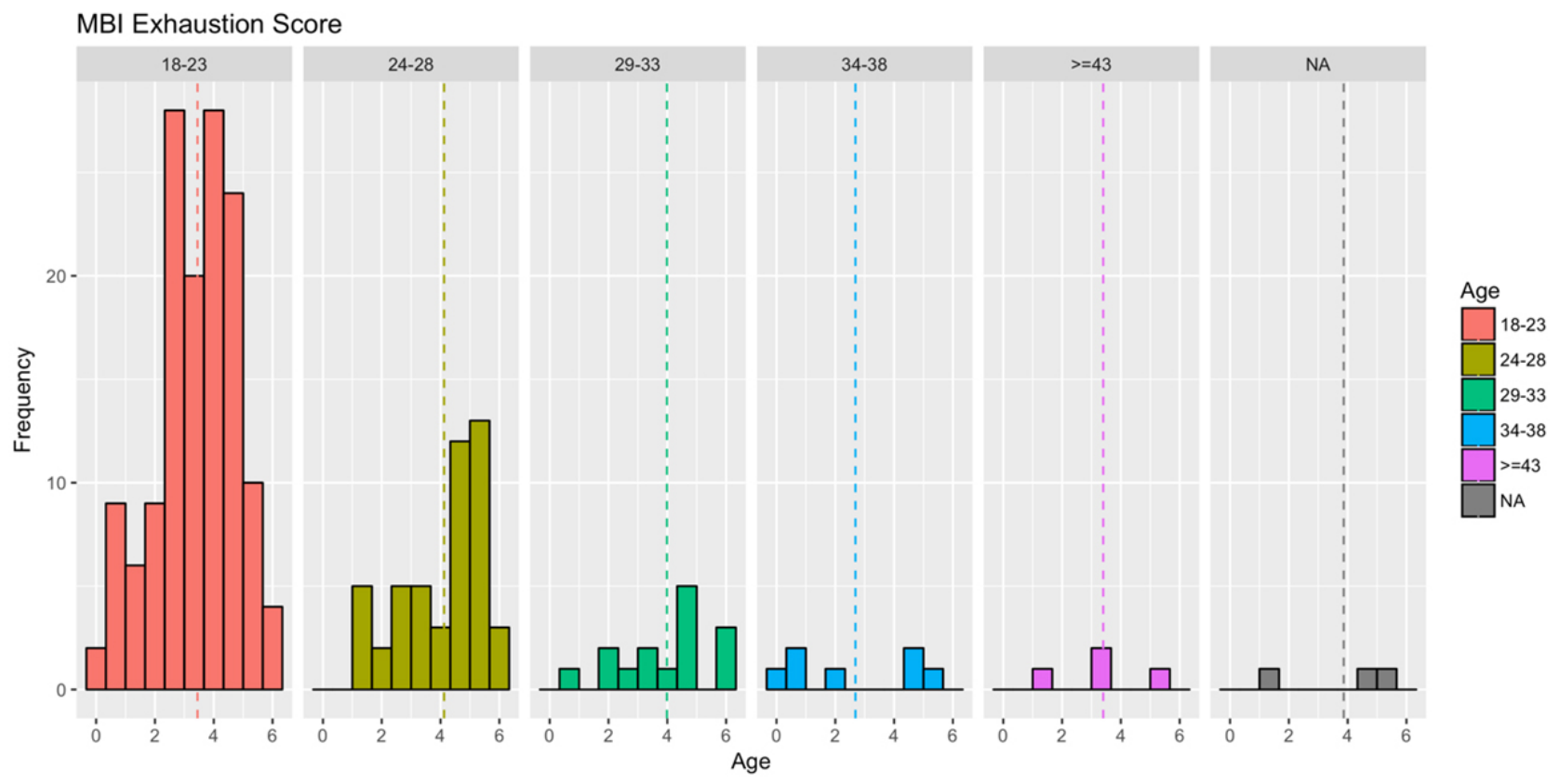

Figure 8. MBI Exhaustion score grouped by age

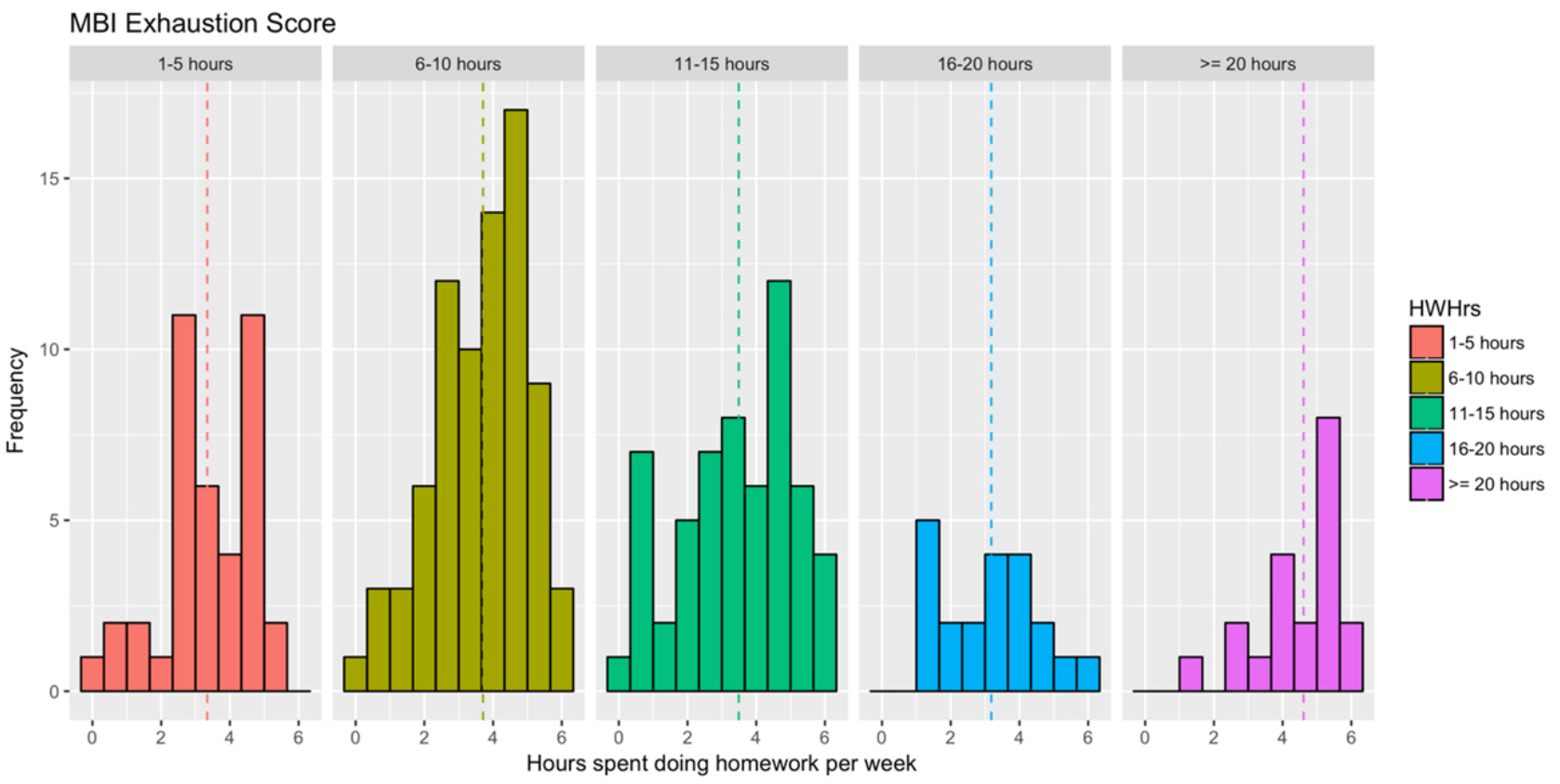

Figure 9. MBI Exhaustion score grouped by hours spent doing homework

Students who spent more than 16 or less than 5 hours studying per week reported higher exhaustion levels (see Figure $10)$.

English speakers were more exhausted on average than students whose primary language at home was not English (see Figure 11).

Students in the MSN program tended to be more exhausted than students in the BSN program (see Figure 12).

On average, undergraduate students had higher professional efficacy than graduate students (see Figure 13).

Students who studied between 6-10 hours per week and more than 20 hours per week reported higher levels of professional efficacy (see Figure 14). 


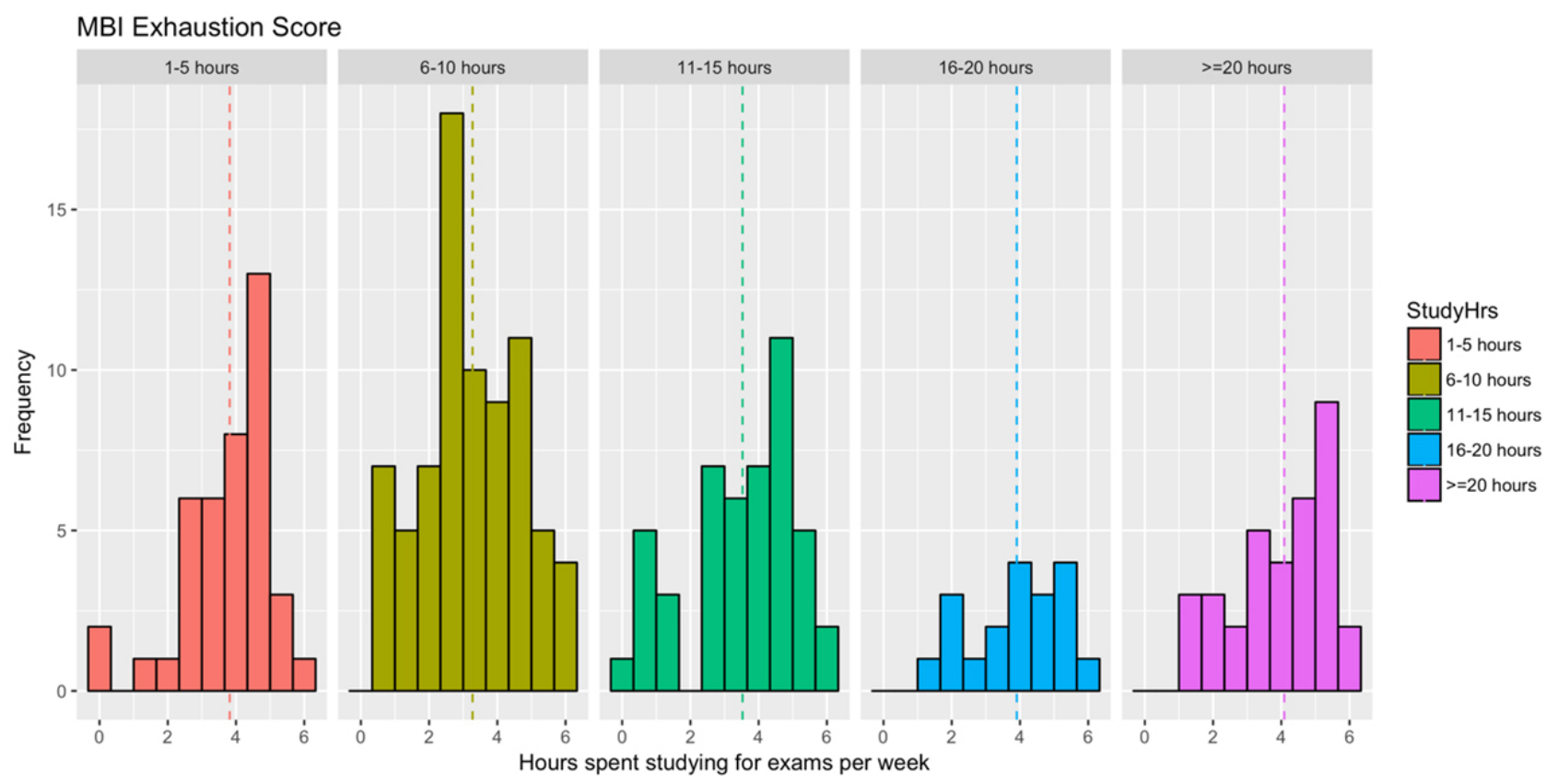

Figure 10. MBI Exhaustion score grouped by hours spent studying for exams

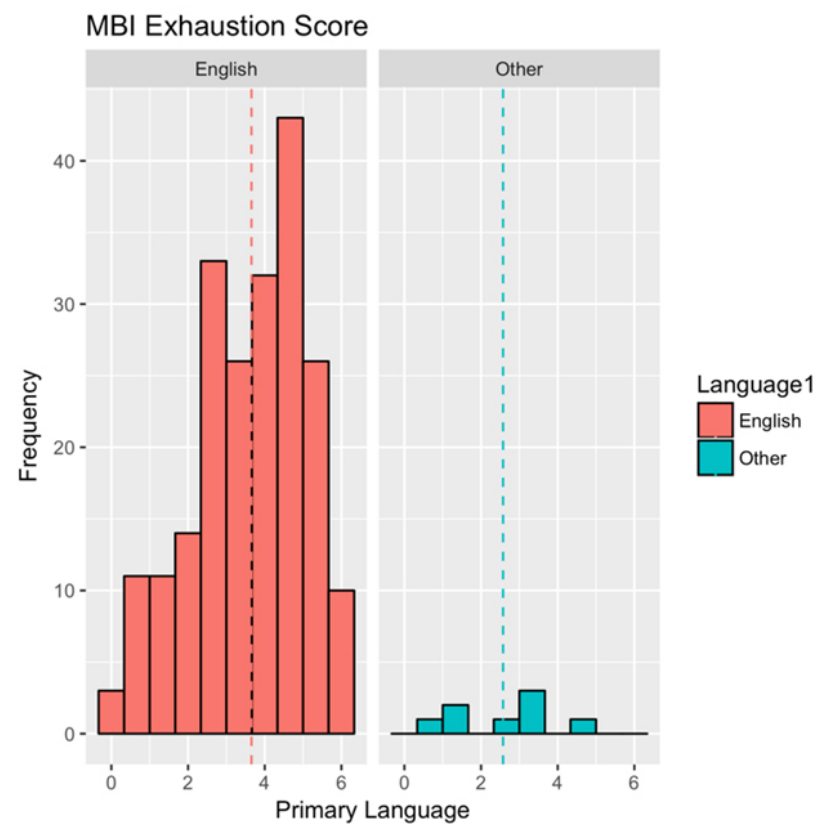

Figure 11. MBI Exhaustion score grouped by whether the primary language spoken at home is English

\section{Discussion}

This study investigated the perceived stress levels and subsequent burnout of undergraduate and graduate nursing students during their Fall 2017 semester at a private University in California. Additionally, the research examined demographic, lifestyle, and environmental factors in the sample population so as to determine potential correlations between each variable and students' perceived stress and burnout lev- els. The results of which, have given credence to previous research that identified nursing students as having significant levels of stress and burnout relative to their coursework, scholarly habits, coping mechanisms, (or lackthereof) and lifestyles. Rees et al.determined maladaptive coping mechanisms positively predicted burnout and poorer adjustment to scholarly life in a population of college-level nursing students $(\mathrm{N}=415) \cdot{ }^{[21]}$

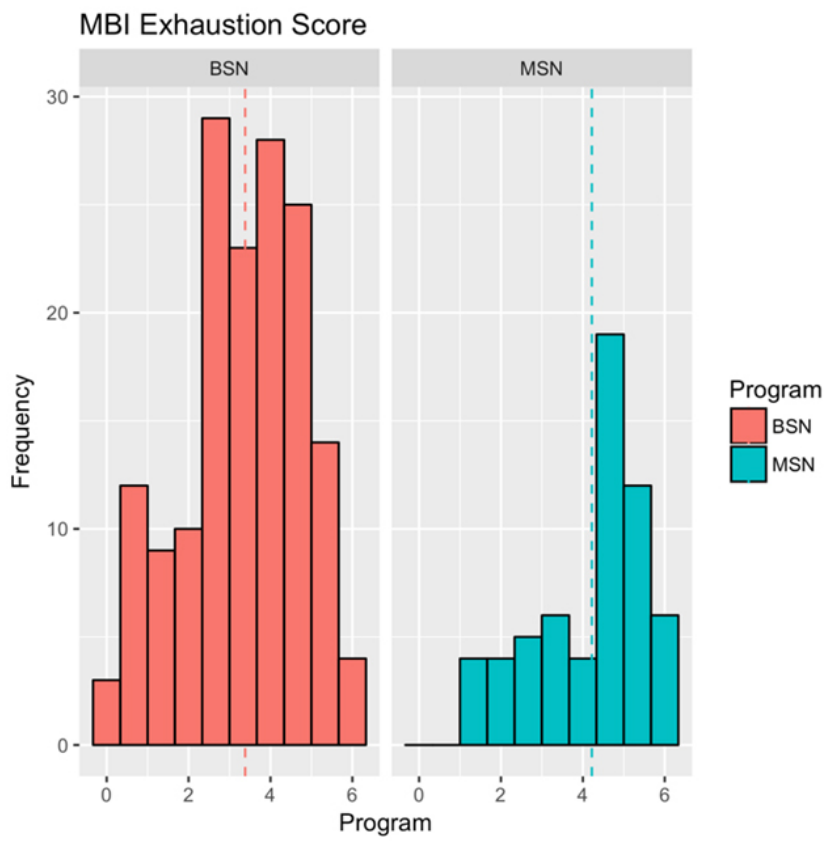

Figure 12. MBI Exhaustion score based on program 


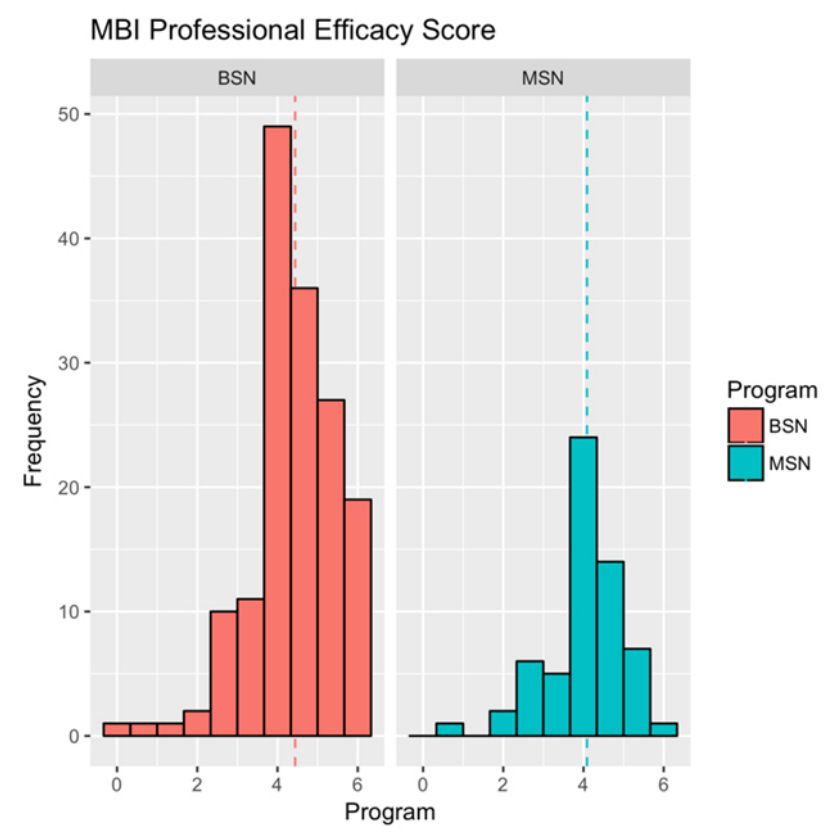

Figure 13. MBI Professional Efficacy score based on program
Previous studies have indicated nursing students have a considerably higher level of perceived scholastic anxieties than the collegiate majority. ${ }^{[22]}$ Anxiety, considered to be a relatively stable personality characteristic, has been found to be key predictor of stress alongside insecurity and a lack of self efficacy, or resilience. ${ }^{[23]}$

While this study expressly investigated a U.S. based sample population, previous research has shown nursing students in various countries and programs experience significant levels of stress, while their coping strategies may differ cross-culturally ${ }^{[3]}$ Nelwati et al., phenomenologically investigated perceived stress amongst nursing students in Indonesia demonstrating academic pressures, interrelationships and coping strategies came into play as indicators of stress. ${ }^{[24]}$ Additionally researchers Silva et al. identified aspects of nursing school that were deleterious to the emotional health of their student population in Brazil, identifying burnout syndrome as a key result. ${ }^{[25]}$ In Turkey, researchers correlated demographic characteristics and means of coping with nursing students stress levels, given that nursing students experienced significant stress. ${ }^{[26]}$

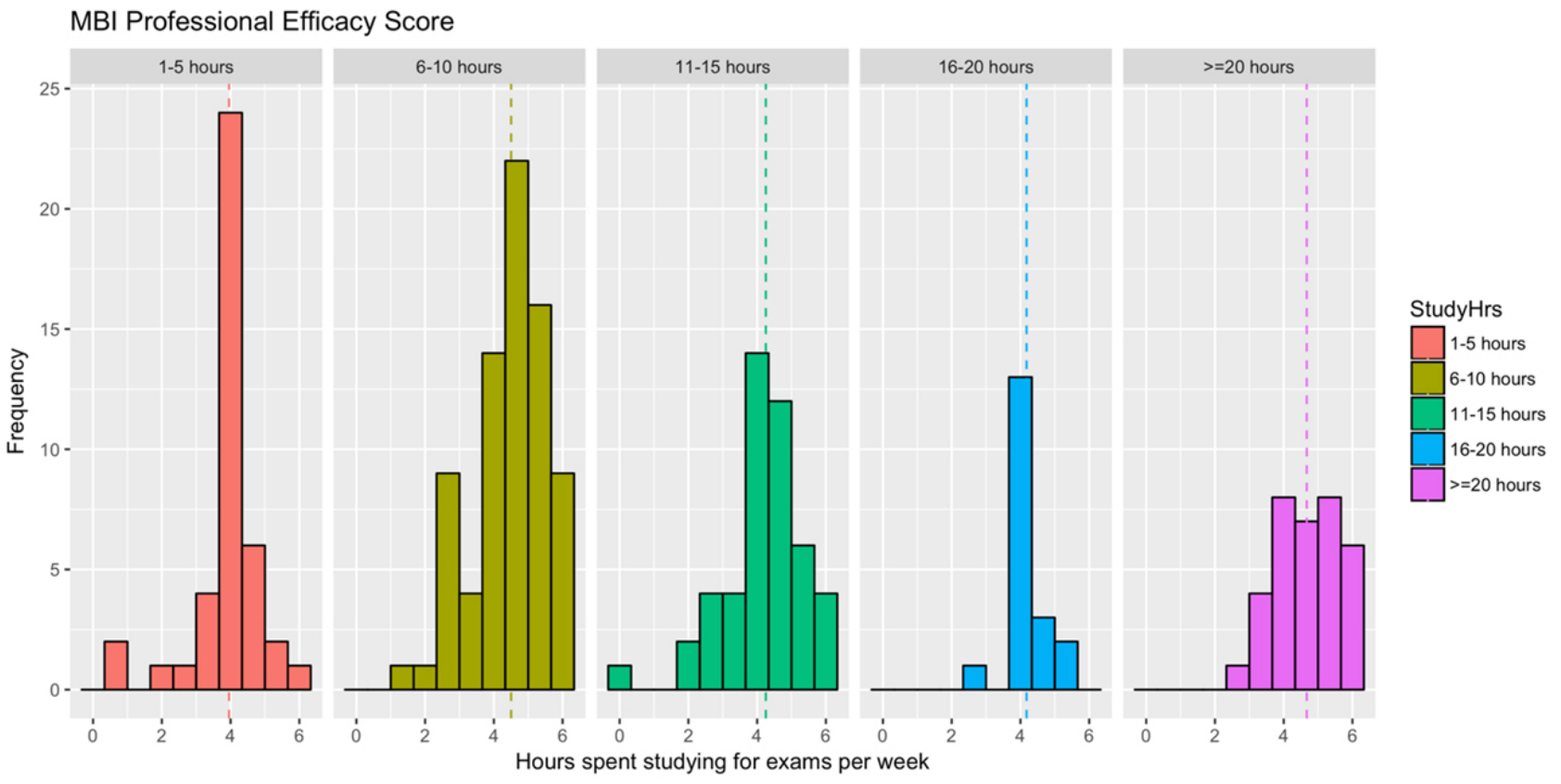

Figure 14. MBI Professional Efficacy score based on hours spent studying for exams each week

As evidenced by Labrague et al. there is meaningful evidence to support the notion that stressed nursing students from across the globe cope with their stress in various ways depending upon their cultural experience and resources. ${ }^{[3]}$ The specific geography and University setting for this study aid the investigators in better understanding the needs of a local culture, where change is more apt to take place with a greater means of measuring success.

There is a dearth of research detailing the specificities of stress indicators and potential correlations with burnout as well as demographic and lifestyle indicators. While further investigation is critical, the results of this study highlight the potential for stress incidence in nursing students. This 
could enable nurse educators, nursing program directors, and health education administrators to better assess stress levels and the impact of stress amongst students.

The results of this study indicate students who spend more hours per week on their scholastic duties tend to be more stressed, and therefore have higher rates of cynicism than their peers who chose not to give as much of their time to coursework. Demographically speaking, students in the 2433 years old age bracket tend to be more cynical than the 18-23 years old bracket, suggesting that age, and subsequent lifestyle factors, factor into their perception of stress.

Additionally 24-28-year olds were more exhausted than 18 23-year olds, whereas 34-38-year olds were marginally less exhausted than their younger peers. While not entirely conclusive data exists to represent why the age groups experienced stress differently, there is much significance to be garnered from lifestyle indicators and nursing students stress perceptions. Graduate students were far more cynical and exhausted than the undergraduates, while the Undergraduates felt a greater sense of professional efficacy. This could be a result of external pressures, and cognitive developmental stages of primarily, 18-23-years olds, but further study would be needed to make appropriate correlations.

With regard to the investigation of extracurricular activities, exposure to the outdoors, and known relaxation practices, yoga, meditation, walking camping and taking art classes had some significant effect on the student populations' perceived stress levels and burnout. However, many variable were investigated and further analysis would be necessary to determine the impact the extracurriculars in question had on stress levels, and what level of engagement or proficiency was required to consider such an activity a true coping mechanism for stress. Questions of access are relevant and specific to the study's sample population.

\section{Limitations}

It is important to note there are a few limitations to this study. One of the limitations is the sample size. While the sample size $(\mathrm{N}=217)$ was adequate for this analysis, it may be insufficient to allow for generalization of the findings to other schools of nursing that educate students to be registered nurses (RNs).

Another limitation is the study was conducted at a private university; therefore, findings may not be generalized to students at all universities. One more limitation is there are less male than female students included in the study due to the convenience population at the SON and the limited number of male students in the nursing programs. The final limitation is one of the professors, without consulting with the PIs or RAs, gave extra credit for the students who completed the surveys. Consequently, the response rate was affected.

\section{Conclusion}

Results of this study indicate that nursing students have significant levels of stress associated with their coursework and studying. Students engaged in specific recreational and stress-reducing activities may have some agency in managing their stress. The findings of this study support the notion that students in healthcare fields are susceptible to stress and may or may not have the tools available to manage their stress depending upon their lifestyles and environmental factors. This calls upon scholastic committees, nursing education departments, and healthcare professionals at large to consider the impact stress has on students and the future of healthcare workers. Being able to manage stress in school is an excellent predictor for being able to manage it in the workforce.

This research supports the evidence that suggests scholastic environments offer stress reduction techniques in their programming in the event that the curriculum cannot undergo a reviso. In the event that colleges and universities are unable to promote and offer stress-reduction systems, and students are unable to access the opportunity in their extracurricular lives, then future researchers must consider how to better inform our healthcare system so as to ensure a reduction of costly burnout syndrome and stress induced retention issues.

Future research could support the notion for better access to stress and burnout reduction systems such as intentioned natural environments were walking, meditation and exercise could be more freely accessible. It is critical for healthcare students and future healthcare workers to have tools to cope with stress and potential burnout for their health and welfare may predict their ability to care for others with any longevity.

\section{ACKNOWLEDGEMENTS}

The authors kindly thank the SON Faculty Development Committee for funding this research project. A special thanks to Research Assistants, Eva Chen and Kelsey Morton for collecting data and Dr. Shannon Halkyard for data analyses assistance.

\section{CONFlicts OF INTEREST Disclosure}

The authors declare that there is no conflict of interest. 


\section{REFERENCES}

[1] Department of Health and Human Resources. Exposure to stress: occupational hazards in hospitals. [cited October 26, 2017]. Available from: https://www.cdc.gov/niosh/docs/2008-136/p dfs/2008-136.pdf

[2] Maslach C, Jackson SE, Leiter MP, et al. Maslach Burnout Inventory. [cited October 26, 2017]. Available from: http: //www.mindgarden.com/117-maslach-burnout-i nventory\#horizontalTab5

[3] Labrague L, Mcenroe-Petitte D, Amri MA, et al. An integrative review on coping skills in nursing students: implications for policymaking. International Nursing Review. 2017.

[4] Alzayyat A, Al-Gamal E. A Review of the Literature regarding Stress among Nursing Students during their Clinical Education. International Nursing Review. 2014; 61(3): 406-15.

[5] Wallace L, et al. Perceptions of Clinical Stress in Baccalaureate Nursing Students. International Journal of Nursing Education Scholarship. 2015; 12(1): 91-8.

[6] Betzabeth S, Benavente T, Costa ALS. Physiological and Emotional Responses to Stress in Nursing Students: An Integrative Review of Scientific Literature. Acta Paulista de Enfermagem. 2011; 24(4): 571-6.

[7] Kang DH, Boss L, Barrientos M, et al. Stress-Related Biobehavioral Profile of Senior Nursing Students. Journal of Nursing Education and Practice. 2015; 5(6): 129-140. http://dx.doi.org/10.5430/j nep.v5n6p129

[8] Shinde MB, Hiremath P. Stressors, Level of Stress and Coping Mechanism Adopted by Undergraduate Nursing Students. International Journal of Nursing Education. 2014; 6(2): 231-3. https : //doi.org/10.5958/0974-9357.2014.00640.0

[9] Hirsch CD, et al. Preditores do Estresse E Estratégias De Coping Utilizadas Por Estudantes De Enfermagem. Acta Paulista de Enfermagem. 2015; 28(3): 224-9. https://doi.org/10.1590/1982 0194201500038

[10] Galbraith ND, Brown KE. Assessing Intervention Effectiveness for Reducing Stress in Student Nurses: Quantitative Systematic Review. Journal of Advanced Nursing. 2011; 67(4): 709-21. PMid:21214619 https://doi.org/10.1111/j.1365-2648.2010.05549.x

[11] Desiree H, Laux M. Longitudinal Study of Stress, Self-Care, and Professional Identity among Nursing Students. Nurse Educator. 2014; 39(5): 227-31. PMid:24867076 https : //doi .org/10.1097/NNE. 0000000000000057

[12] Cohen S, Kamarck T, Mermelstein R. A Global Measure of Perceived Stress. Journal of Health and Social Behavior. 1983; 24(4): 385. https://doi.org/10.2307/2136404
[13] Maslach C, Jackson SE, Leiter MP. Maslach burnout inventory manual. 4th ed. Palo Alto (CA): Consulting Psychologists Press; 2016.

[14] University of San Francisco School of Nursing and Health Professions BSN Program Student Handbook. University of San Francisco, San Francisco; Aug. 2017.

[15] Sawatzky JAV. Understanding nursing students stress: a proposed framework. Nurse Education Today. 1998; 18(2): 108-15.

[16] Pollock S. The stress response. Critical Care Quarterly. 1984; 3: 1-13.

[17] Maslach C, Leiter MP. Early predictors of job burnout and engagement. Journal of Applied Psychology. 2008; 93(3): 498-512. PMid:18457483 https://doi.org/10.1037/0021-9010.93.3 .498

[18] Cohen S, Janicki-Deverts D. Whos Stressed? Distributions of Psychological Stress in the United States in Probability Samples from 1983, 2006, and 2009. Journal of Applied Social Psychology. 2012; 42(6): 1320-34.

[19] Iwanicki EF, Schwab RL. A cross-validational study of the Maslach burnout inventory. Educational and Psychological Measurement. 1981; 41: 1167-1174. https://doi.org/10.1177/0013164481 04100425

[20] The R Project for Statistical Computing [Internet]. [cited 2018 March1]. Available from: https : //www.r-project.org/

[21] Rees CS, Heritage B, Osseiran-Moisson R, et al. Can We Predict Burnout among Student Nurses? An Exploration of the ICWR-1 Model of Individual Psychological Resilience. Frontiers in Psychology. 2016.

[22] Wedgeworth M. Anxiety and education: An examination of anxiety across a nursing program. Journal of Nursing Education and Practice. 2016; 6(10): 23-32. https ://doi.org/10.5430/jnep.v6n10p2 3

[23] Meijer J. Stress in The Relation Between Trait And State Anxiety. Psychological Reports. 2001; 88(3): 947. https : //doi.org/10.2 466/PR0.88.3.947-964

[24] Nelwati, Mckenna L, Plummer V. Indonesian student nurses' perceptions of stress in clinical learning: A phenomenological study. Journal of Nursing Education and Practice. 2013; 3(5): 56-65. https://doi.org/10.5430/jnep.v3n5p56

[25] Silva RMD, Guido LDA, Lopes LFD, et al. Impact of nursing students' profile on burnout syndrome and hardiness personality. Journal of Nursing Education and Practice. 2017; 7(10): 19-26. https://doi.org/10.5430/jnep.v7n10p19

[26] Yeşil P, Öztunç G, Eskimez Z. Personal characteristics and styles of coping with stress of nursing students of a university in Turkey. Journal of Nursing Education and Practice. 2015 Oct; 5(5): 73-81. https://doi.org/10.5430/jnep.v5n5p73 